\title{
The Cementite Spheroidization Process in High-Carbon Steels with Different Chromium Contents
}

\begin{abstract}
N.V. LUZGINOVA, L. ZHAO, and J. SIETSMA
The cementite spheroidization process is investigated in hypereutectoid steels with different chromium $(\mathrm{Cr})$ contents. A spheroidized structure in high-carbon steel is usually obtained by a divorced eutectoid transformation (DET) reaction, which occurs during slow cooling of austenite with fine cementite particles. A bimodal distribution of spheroidized cementite particles is experimentally observed. It is shown that $\mathrm{Cr}$ addition allows one to obtain the spheroidized structure after austenitization at a higher temperature and a longer annealing time as compared with low-Cr steel. It is found that the DET reaction takes place at low undercoolings compared with the pearlitic reaction. The occurrence of the DET reaction also depends strongly on the spacing between cementite particles during the austenitization process, i.e., on austenitization temperature and time.
\end{abstract}

DOI: $10.1007 / \mathrm{s} 11661-007-9403-3$

(C) The Authors(s) 2008

\section{INTRODUCTION}

THE spheroidization annealing, which results in a microstructure of fine spherical cementite particles in a soft ferritic matrix, ${ }^{[1]}$ is of significant interest for industrial applications. The main purpose of this process is to reduce the hardness of the material and thus provide a good machinability prior to further processing. ${ }^{[2]}$ Two types of spheroidization annealing are often used. (1) Subcritical spheroidization below the $A_{1}$ temperature, which is mainly applied for hypoeutectoid steels. During subcritical annealing of steels with an initial pearlite structure, the cementite lamellae break up into spheroids driven by the reduction in surface energy. ${ }^{[3,4]}$ (2) Intercritical spheroidization above the $A_{1}$ temperature, which is mainly applied for hypereutectoid steels in order to spheroidize and partially dissolve the grain boundary cementite. Therefore, the final microstructure of spheroidized hypereutectoid steels usually contains a bimodal distribution of cementite particles, ${ }^{[5,6]}$ where large particles are located mainly on austenite grain boundaries. Numerical simulations of the intercritical spheroidization process in a high-carbon steel have shown that the rate of dissolution of the cementite lamellae also depends on the surrounding conditions. ${ }^{[7]}$ This research will focus on the intercritical spheroidization annealing.

The spheroidization process of hypereutectoid steels, for instance SAE 52100 bearing steel with $1 \mathrm{wt}$ pet $C,{ }^{[5-9]}$ typically consists of the following three steps:

N.V. LUZGINOVA, Postdoctoral Researcher, and L. ZHAO, Research Fellow, are with the Netherlands Institute for Metals Research and the Department of Materials Science and Engineering, Delft University of Technology, 2628 CD Delft, The Netherlands. Contact e-mail: n.v.luzginova@tudelft.nl J. SIETSMA, Associate Professor, is with the Department of Materials Science and Engineering, Delft University of Technology, Delft, The Netherlands.

Manuscript submitted June 20, 2007.

Article published online January 30, 2008 austenitization in the intercritical region at 1070 to $1100 \mathrm{~K}$ for at least 1 hour; (2) cooling from the intercritical temperature with a rate of 15 to $25 \mathrm{~K} / \mathrm{h}$ to $1020 \mathrm{~K}$, and further slow cooling through the $A_{1}$ temperature to $950 \mathrm{~K}$ at cooling rates not faster than 5 to $10 \mathrm{~K} / \mathrm{h}$; and (3) air cooling from $1020 \mathrm{~K}$ to room temperature. Annealing above the $A_{1}$ temperature but below the $A_{c m}$ temperature accomplishes an incomplete dissolution of cementite, then austenite with fine cementite particles normally transforms into a mixture of ferrite and cementite by either the pearlitic reaction ${ }^{[10]}$ or by the divorced eutectoid transformation reaction $(\mathrm{DET})^{[5,8,9,11]}$ upon slow cooling. The latter leads to a soft microstructure of spherical cementite particles in a ferritic matrix. The main difference between these two reactions is that during the pearlitic reaction the product structure (pearlite) grows as a coupled pair of ferrite and cementite phases, whereas the DET is not a coupled reaction and requires the presence of fine but densely distributed cementite particles in the austenite. These particles grow when the austenite to ferrite transformation front passes, without nucleation of new cementite particles. In general, more carbon diffusion is required for the DET reaction. These two reactions compete during cooling from the austenitization temperature. The occurrence of either the pearlitic or the DET reaction will therefore depend strongly on the spacing between cementite particles, i.e., on the austenitization temperature and time, and on the cooling rate where slower cooling rates are favorable for the DET reaction.

Chromium $(\mathrm{Cr})$ additions have a significant influence on the spheroidization of cementite. Oyama ${ }^{[11]}$ has shown that a DET-promoted spheroidized structure can be easily obtained in an ultra-high carbon steel with 1.5 wt pct $\mathrm{Cr}$, but not in the equivalent $\mathrm{Cr}$-free steel. In Cr-free steel pearlite formation has been observed even after low-temperature intercritical austenitization. Beswick $^{[12]}$ has studied the effect of $\mathrm{Cr}$ in bearing steels by lowering its content from $1.42 \mathrm{wt}$ pct (SAE 52100 
steel) to $0.03 \mathrm{wt}$ pct and demonstrated that a decrease in $\mathrm{Cr}$ content in hypereutectoid steels influences the carbide particle size. The experiment to obtain a similar spheroidized structure with different $\mathrm{Cr}$ contents was not fully successful, and the finer microstructure in steels with higher $\mathrm{Cr}$ content was explained from the finer initial pearlite lamellae spacing. Verhoeven ${ }^{[5]}$ has given an alternative explanation for the finer cementite size in high-Cr steels. The cementite particle size is controlled by the spheroidization/dissolution rate at the austenitization temperature and this rate is reduced by the addition of carbide-forming elements such as $\mathrm{Cr}$ and $\mathrm{Mn}$. However, Mn is found to promote pearlite formation during the spheroidization process. ${ }^{[5]}$ Consequently, the effect of $\mathrm{Cr}$, particularly at lower $\mathrm{Cr}$ contents, and other alloying elements on the DET reaction is not well understood yet.

In this research, spheroidization processes are designed on the basis of thermodynamic and kinetic calculations for hypereutectoid steels with different $\mathrm{Cr}$ contents varying from 0.5 to $3.4 \mathrm{wt}$ pct. The microstructural evolution is observed and quantified using optical microscopy. The mechanism of the DET reaction in hypereutectoid steels is discussed and the effect of $\mathrm{Cr}$ additions on the DET reaction is explained.

\section{EXPERIMENTAL PROCEDURE}

The steel compositions studied are listed in Table I. The $\mathrm{Cr}$ content is varied between 0.5 and $3.4 \mathrm{wt}$ pct, while the concentrations of the remaining alloying elements ( $\mathrm{C}, \mathrm{Si}$, and $\mathrm{Mn})$ are almost the same as in SAE 52100 steel. It should be noted that the $1.5 \mathrm{Cr}$ steel is equivalent to the commercial SAE 52100 bearing steel. All alloys were manufactured by chill casting under inert conditions using high-purity alloying metals, resulting in ingot dimensions of $40 \times 40 \times 160 \mathrm{~mm}^{3}$. After casting, a chemical analysis of each ingot was made and hot isostatic pressing (HIP) was performed at a temperature of $1420 \mathrm{~K}$ under a pressure of $100 \mathrm{MPa}$ for 4 hours, followed by furnace cooling to $1070 \mathrm{~K}$ at an average rate of $12 \mathrm{~K} / \mathrm{min}$ and cooling to room temperature at an average rate of $35 \mathrm{~K} / \mathrm{min}$, in order to obtain a pore-free and homogenized structure.

Thermodynamic calculations were performed using the ThermoCalc software* (TCCR version, TCFE2

\footnotetext{
*ThermoCalc is a trademark of ThermoCalc Software Inc., SE-113 47 Stockholm, Sweden.

database) to develop an appropriate spheroidization process. In order to obtain the time dependence of the cementite fraction as well as the cementite particle spacing at the different austenitization temperatures, the dissolution of cementite was simulated with DICTRA**[13]
}

\footnotetext{
**DICTRA is a trademark of ThermoCalc Software Inc., SE-113 47 Stockholm, Sweden.
}

Table I. Steel Compositions in Weight Percent

\begin{tabular}{lcccc}
\hline Steel & $\mathrm{C}$ & $\mathrm{Si}$ & $\mathrm{Mn}$ & $\mathrm{Cr}$ \\
\hline $0.5 \mathrm{Cr}$ & 1.04 & 0.25 & 0.30 & 0.53 \\
$1.5 \mathrm{Cr}$ & 1.05 & 0.25 & 0.34 & 1.44 \\
$2.5 \mathrm{Cr}$ & 1.04 & 0.27 & 0.31 & 2.39 \\
$3.5 \mathrm{Cr}$ & 1.02 & 0.27 & 0.30 & 3.38 \\
\hline
\end{tabular}

(version 22, TCFE2 database for thermodynamic data and MOB2 database for mobility data).

The designed heat treatments were carried out in a Bähr 805 dilatometer (Bähr-Thermoanalyse $\mathrm{GmbH}$, D-32609 Hüllhorst, Germany) using cylindrical specimens with a diameter of $5 \mathrm{~mm}$ and a length of $10 \mathrm{~mm}$. The microstructures were quantitatively analyzed using AnalySIS image processing software (Olympus Soft Imaging Solutions GmbH, D-48149 Münster, Germany). To obtain a good contrast for the optical analysis all specimens were pre-etched in 5 pct Nital followed by Klemm's tint etching $(50 \mathrm{~mL}$ of saturated aqueous sodium thiosulfate solution and $1 \mathrm{~g}$ of sodium disulfide); after etching cementite appears in white and ferrite in black, which enables a reliable setting for the threshold value for further quantitative analysis of size and volume fraction of cementite. The Vickers hardness of all specimens was measured using the Buehler automatic microhardness testing system OmniMent MHT 7.0 rev. 1 (Buehler GmbH, D-40599 Düsseldorf, Germany) with a load of $1 \mathrm{~kg}$. The hardness presented is the average of at least five values.

\section{RESULTS}

\section{A. Design of the Spheroidization Heat Treatment}

In order to establish an appropriate spheroidization heat treatment and to take the effect of $\mathrm{Cr}$ into account, the phase diagrams were calculated using ThermoCalc software. Figure 1(a) presents the quasi-binary $\mathrm{Fe}-\mathrm{C}$ phase diagrams, and Figure 1(b) shows the temperature dependence of the cementite fraction for the investigated steels (Table I). Three-phase regions (ferrite, austenite, and cementite), which split $A_{1}$ into two lines, are observed in the phase diagrams for all steels. Lower and upper $A_{1}$ temperatures are presented as $A_{1}$ and $A^{\prime}{ }_{1}$, respectively, in Figure 1. Characteristic temperatures from the phase diagram are listed in Table II, and it can be seen that the addition of alloying elements changes the phase equilibria for these steels. The increase in $\mathrm{Cr}$ content, for instance, raises the $A_{1}$ and $A^{\prime}{ }_{1}$ temperatures, slightly widens the three-phase region, and shifts the eutectoid composition to lower carbon concentration (Figure 1, Table II).

As suggested in Reference 5, the DET reaction usually occurs at slow cooling and after austenitization at lower temperatures compared with the pearlitic reaction. This research focuses on the influence of the austenitization temperature and time on the spheroidization process, therefore the cooling rate has been kept constant. The entire proposed spheroidization heat treatment is shown 


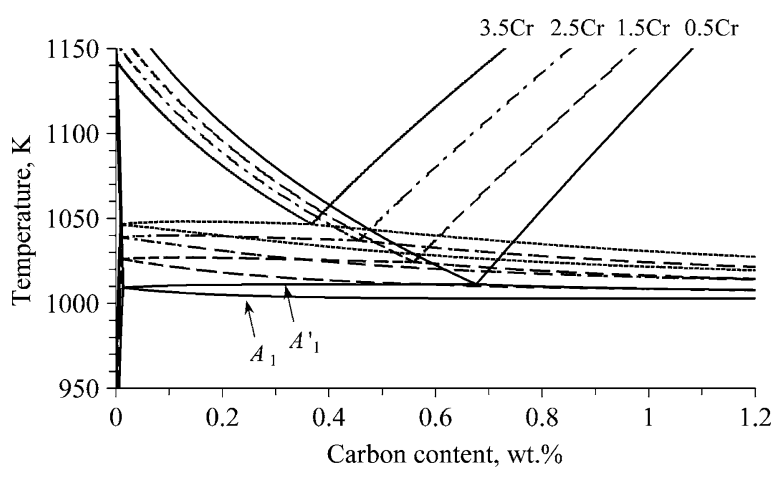

(a)

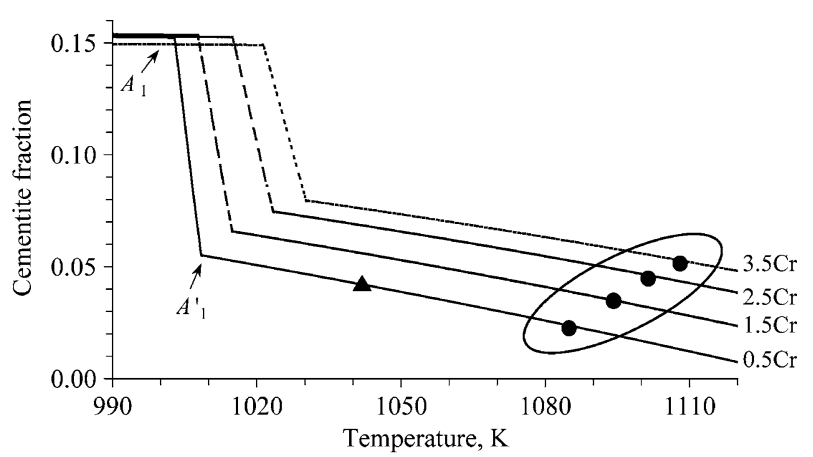

(b)

Fig. 1-(a) Quasi-binary Fe-C phase diagrams. (b) Cementite fraction $v s$ temperature for steels with four different $\mathrm{Cr}$ contents. Solid circles represent austenitization temperatures $A_{1}^{\prime}+75 \mathrm{~K}$. Solid triangle shows improved austenitization temperature for $0.5 \mathrm{Cr}$ steel.

Table II. Characteristic Temperatures and Eutectoid Compositions

\begin{tabular}{lccc}
\hline Steel & $A_{1}(\mathrm{~K})$ & $A^{\prime}{ }_{1}(\mathrm{~K})$ & $C_{\text {eut }}(\mathrm{Wt} \mathrm{Pct})$ \\
\hline $0.5 \mathrm{Cr}$ & 1003 & 1008 & 0.67 \\
$1.5 \mathrm{Cr}$ & 1008 & 1015 & 0.56 \\
$2.5 \mathrm{Cr}$ & 1015 & 1023 & 0.45 \\
$3.5 \mathrm{Cr}$ & 1021 & 1030 & 0.37 \\
\hline
\end{tabular}

in Figure 2. At first, the heat treatment proposed for commercial SAE 52100 steel $^{[1,5]}$ has been used, i.e., the austenitization time $t_{1}$ is taken to be 3 hours and the austenitization temperature $T_{1}=A^{\prime}{ }_{1}+75 \mathrm{~K}$, with a cooling rate of $15 \mathrm{~K} / \mathrm{h}$ from the austenitization temperature to $10 \mathrm{~K}$ above $A^{\prime}{ }_{1}$, followed by cooling at $5 \mathrm{~K} / \mathrm{h}$ to $955 \mathrm{~K}$. As shown later, different $T_{1}$ and $t_{1}$ are used to promote the DET reaction and to improve the spheroidization heat treatment for the $0.5 \mathrm{Cr}$ steel.

\section{B. Microstructural Observations and Hardness Measurement}

The initial microstructures of hypereutectoid Cr-containing steels after casting and HIP consist of pearlite and proeutectoid cementite at the prior austenite grain boundaries (Figures 3(a), (c), (e), and (g)). The hardness of these microstructures is in the range of 280 to $370 \mathrm{HV}$, as shown in Figure 4. The hardness increases

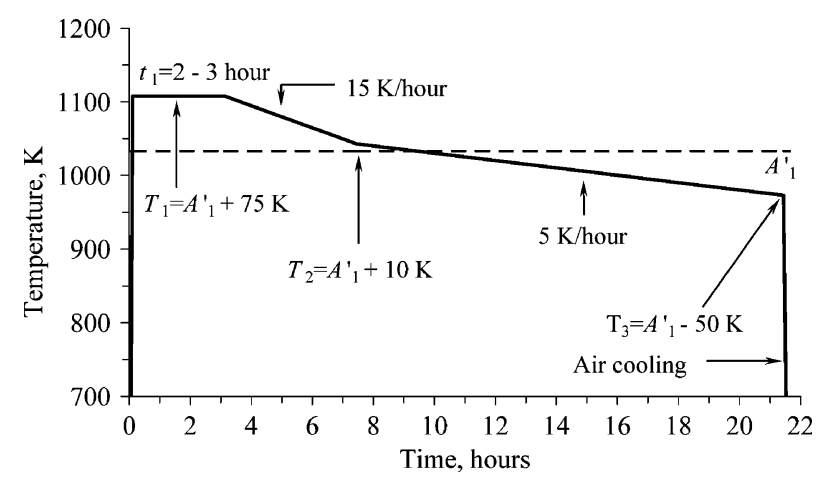

Fig. 2- Spheroidization heat treatment for investigated steels.

with increasing $\mathrm{Cr}$ content as a result of the smaller grain size (Figure 3). The volume fraction of proeutectoid cementite according to the phase diagram changes from 0.06 in $0.5 \mathrm{Cr}$ steel to 0.10 in $3.5 \mathrm{Cr}$ steel, whereas the total equilibrium volume fraction of cementite at room temperature in all steels is around 0.15 (Figure 1). Such a pearlitic microstructure has a poor machinability, which is considered to be a disadvantage for industrial applications. In order to overcome these problems, the spheroidization annealing as described in the previous section is performed. The austenitization temperatures are $1085,1095,1100$, and $1110 \mathrm{~K}$ for the $0.5 \mathrm{Cr}, 1.5 \mathrm{Cr}, 2.5 \mathrm{Cr}$, and $3.5 \mathrm{Cr}$ steels, respectively, i.e., $T_{1}=A^{\prime}{ }_{1}+75 \mathrm{~K}$. During the spheroidization annealing the dilatation signal has been recorded, and during cooling the austenite-ferrite transformation starting temperatures $T_{\text {start }}$ are determined from the dilatometry experiments. The undercoolings $\Delta T=A_{1}^{\prime}-T_{\text {start }}$ are found to be different for different heat treatments and $\mathrm{Cr}$ contents, and will be discussed subsequently.

The microstructure after the spheroidization heat treatment is presented in Figures 3(b), (d), (f), and (h). The $1.5 \mathrm{Cr}, 2.5 \mathrm{Cr}$, and $3.5 \mathrm{Cr}$ steels (Figures $3(\mathrm{~d})$, (f), and (h)) demonstrate a well-spheroidized structure, while the $0.5 \mathrm{Cr}$ steel does not show a complete spheroidization of cementite (Figure 3(b)), and the aspect ratio of the cementite particles varies from 1.2 to 10 . The microstructure of this steel consists of islands of newly formed pearlite and large spherical cementite particles. To improve the spheroidization, the heat treatment is redesigned based on the idea that the austenite at the $T_{1}$ temperature should contain a sufficiently high density of undissolved cementite particles. In the case of the $0.5 \mathrm{Cr}$ steel, the reason for the formation of pearlite instead of a spheroidized structure is either a too high austenitization temperature (1085 K) or an excessively long austenitization time ( 3 hours). This results in a greatly pronounced dissolution of cementite. At high austenitization temperature cementite can also start to coarsen by Ostwald ripening. ${ }^{[14]}$ The large spacing between cementite particles subsequently promotes the formation of new colonies of pearlite during cooling.

To verify this idea, three more experiments were performed. The austenitization time was reduced from 3 hours to $10 \mathrm{~min}$ at $1085 \mathrm{~K}$, which did not produce any 

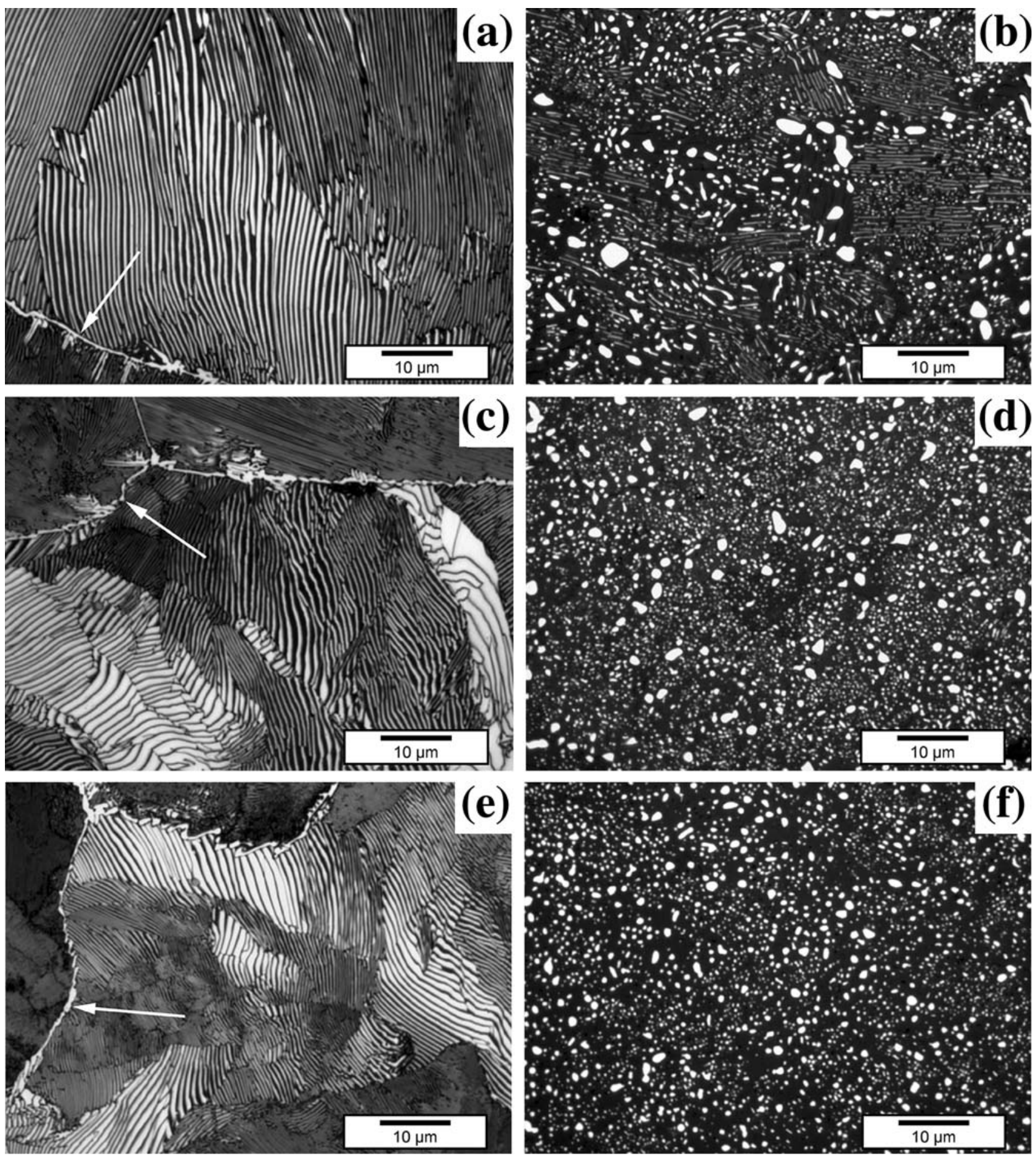

Fig. 3-Microstructure of $(a),(c),(e)$, and $(g)$ as-cast and HIP material and $(b),(d),(f)$, and $(h)$ spheroidized structure obtained according to heat treatment of Fig. 2 for (a) and (b) $0.5 \mathrm{Cr}$, (c) and (d) $1.5 \mathrm{Cr}$, (e) and (f) $2.5 \mathrm{Cr}$, and (g) and (h) $3.5 \mathrm{Cr}$ steels. White arrows indicate the presence of grain boundary cementite. (i) Gray-value distribution of microphotograph of a spheroidized microstructure after Klemm's etching.

significant change in the final microstructure of the $0.5 \mathrm{Cr}$ steel. Then the temperature dependence of the cementite fraction was considered (Figure 1(b)) in order to choose a lower temperature for austenitization of the $0.5 \mathrm{Cr}$ steel. For successfully spheroidized alloys $(1.5 \mathrm{Cr}$, $2.5 \mathrm{Cr}$, and $3.5 \mathrm{Cr}$ ) the volume fraction of cementite has been found to be between 0.04 and 0.06 at the austenitization temperature, whereas in the $0.5 \mathrm{Cr}$ steel it is only 0.025 at $1085 \mathrm{~K}$. In the $0.5 \mathrm{Cr}$ steel a cementite volume fraction of 0.04 is expected after austenitization at $1045 \mathrm{~K}$ (Figure 1(b), triangle).

The obtained microstructure shows a completely spheroidized microstructure (Figure 5(a)) with a network of grain boundary cementite (Figure 5(b)). However, the 

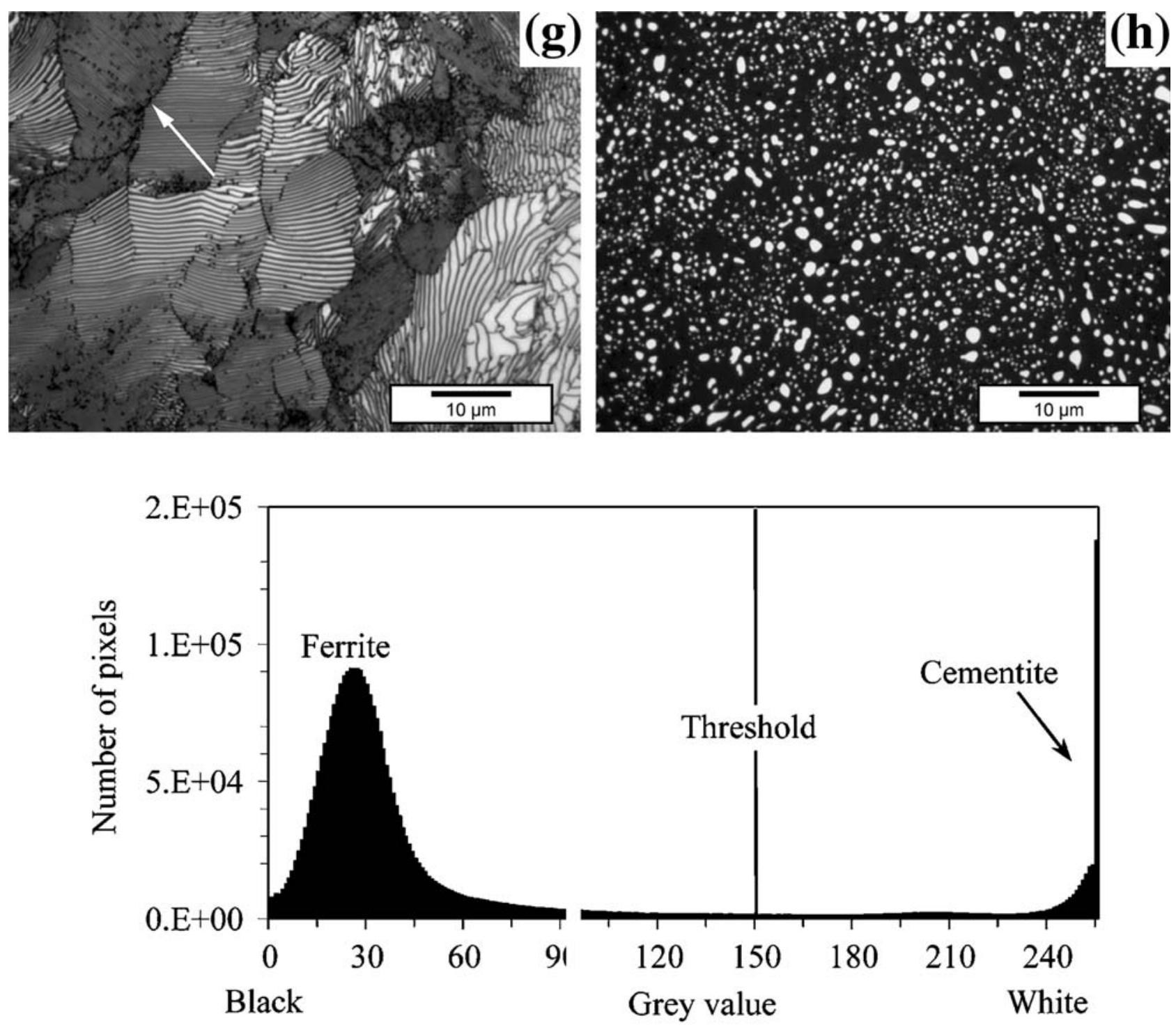

(i)

Fig. 3 - continued.

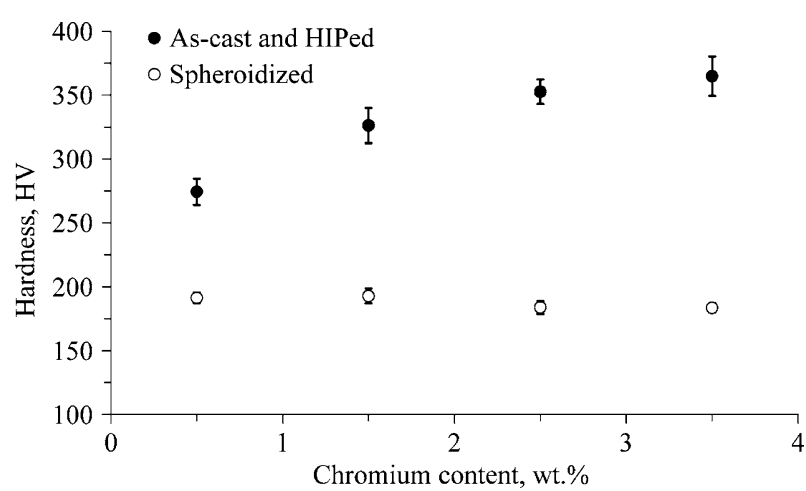

Fig. 4-Hardness of as-cast/HIP and spheroidized steels with different $\mathrm{Cr}$ content. Data for $0.5 \mathrm{Cr}$ steel after improved spheroidization heat treatment. cementite network is not continuous and particles are isolated from each other. It should be noted that the austenitization at $1045 \mathrm{~K}$ is performed for 2 hours, and this time is apparently not long enough to sufficiently reduce the cementite network. Austenitization at $1045 \mathrm{~K}$ is then prolonged to 5.5 hours which, according to the calculated diffusional distances, should be long enough to completely break up the grain-boundary cementite network. However, during cooling after austenitization at $1045 \mathrm{~K}$ for 5.5 hours the formation of lamellar cementite is observed (Figure 5(c)), which was likely due to particle coarsening during austenitization. The spheroidized microstructure obtained after austenitization at $1045 \mathrm{~K}$ for 2 hours (Figures 5(a) and (b)) is considered to be optimal for $0.5 \mathrm{Cr}$ steel.

The measured hardness for all steels is presented in Figure 4. It should be noted that after spheroidization 

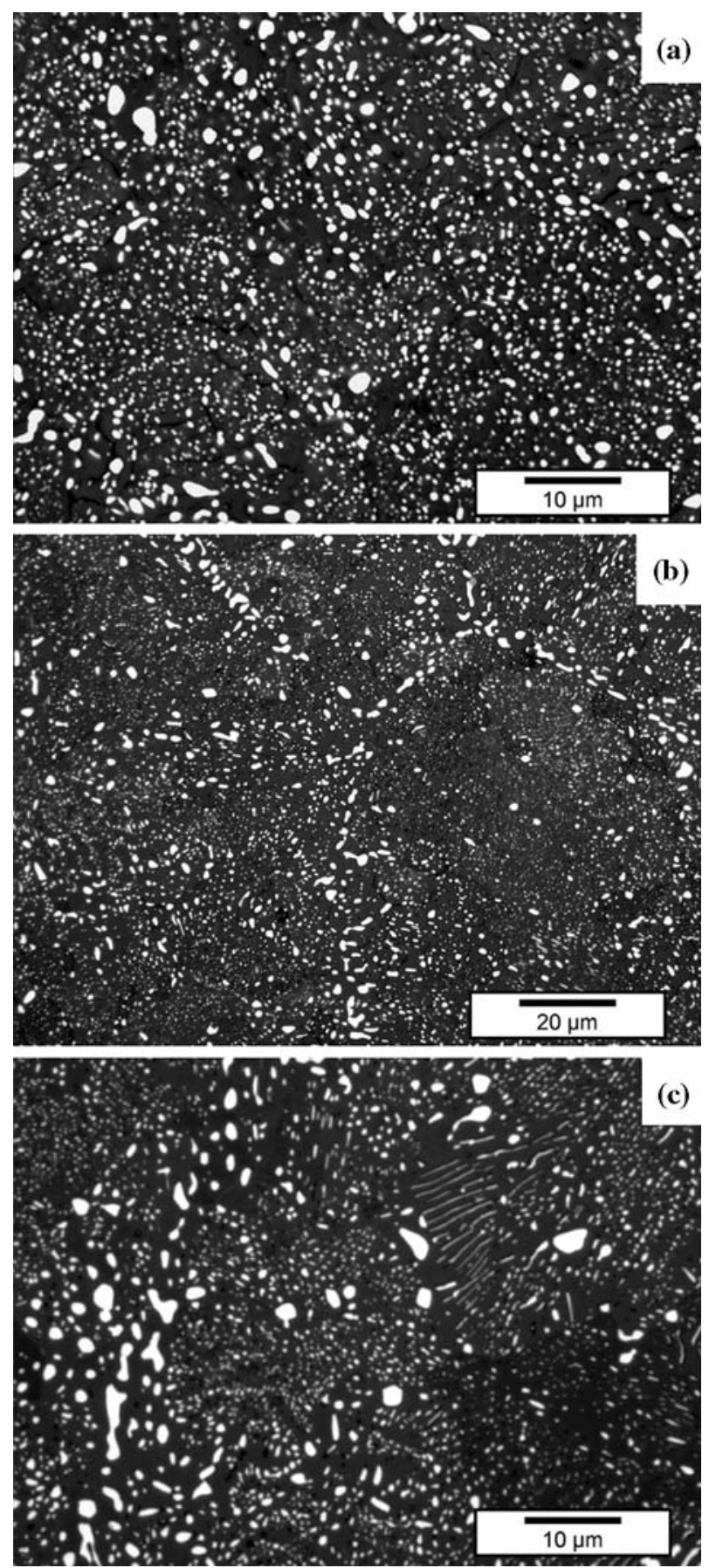

Fig. 5-Microstructure of $0.5 \mathrm{Cr}$ steel after different spheroidization heat treatments. (a) and (b) $1045 \mathrm{~K}$ for $2 \mathrm{~h}$ followed by slow cooling through the $A_{1}^{\prime}$ temperature (different magnifications). (c) $1045 \mathrm{~K}$ for $5.5 \mathrm{~h}$ followed by slow cooling through the $A^{\prime}{ }_{1}$ temperature.

the hardness is found to be around $190 \mathrm{HV}$ for all steels, independent of $\mathrm{Cr}$ content. The variation in the different measurements (the error bars) appears to be very small compared with that for pearlitic microstructures (Figure 4), which is an indication of a uniform spheroidized microstructure with the same particle size distribution. It is known ${ }^{[1,9]}$ that the hardness of the material is directly related to the degree of spheroidization, size, and spatial distribution of spheroidized particles. It seems that the particle size and the size distribution play a dominant role in hardness rather than the composition.

\section{Quantitative Analysis of Spheroidized Microstructures}

All spheroidized microstructures are quantitatively analyzed using image analysis software. To set a reliable threshold value (Figure 3(i)) for analysis, a tint-etching technique has been used, which makes cementite appear in white and ferrite in black/brown. Typically more than 15,000 particles per alloy were analyzed, giving a sufficient statistical sampling area. The size distributions of cementite particles for the $0.5 \mathrm{Cr}, 1.5 \mathrm{Cr}, 2.5 \mathrm{Cr}$, and 3.5Cr steels are shown in Figure 6. A bimodal distribution of particles is observed. The particle size distribution is normally described using a lognormal distribution function. ${ }^{[15]}$ Due to the presence of two clear peaks in the probability function distribution $P(d)$, the size distribution of the cementite particles is fitted using the summation of two lognormal distribution functions:

$$
\begin{aligned}
P(d)= & P(d)_{S}+P(d)_{L} \\
= & \frac{f_{S}}{S_{S} d \sqrt{2 \pi}} \exp \left(\frac{-\left(\ln (d)-M_{S}\right)^{2}}{2 S_{S}^{2}}\right) \\
& +\frac{f_{L}}{S_{L} d \sqrt{2 \pi}} \exp \left(\frac{-\left(\ln (d)-M_{L}\right)^{2}}{2 S_{L}^{2}}\right)
\end{aligned}
$$

where $f_{i}$ is the volume fraction of cementite particles, subscript $i$ relates to the small or large particles, and $f_{S}+f_{L}=1, d$ is the particle diameter, the mean $d_{i}$ and the standard deviation $\sigma_{i}$ of the distributions are given

through $M_{i}$ and $S_{i}$, as $d_{i}=\exp \left(M_{i}+1 / 2 S_{i}^{2}\right)$ and $\sigma_{i}=\sqrt{\exp \left(2 M_{i}+2 S_{i}^{2}\right)-\exp \left(2 M_{i}+S_{i}^{2}\right)}$. From fitting of the experimental results with Eq. [1], where $M_{i}, S_{i}$, and $f_{i}$ are fitting parameters, the volume fractions, mean particle sizes, and standard deviations of the small and large particles are obtained.

A summary of the results for the spheroidization heat treatment is presented in Table III. The degree of

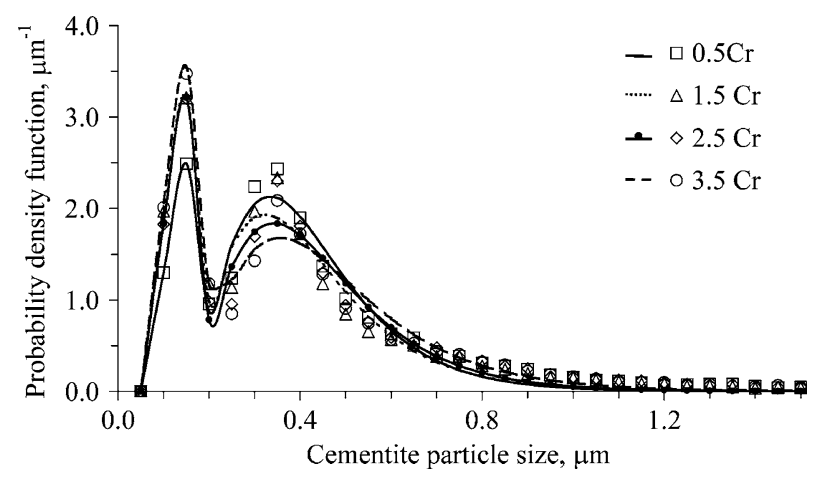

Fig. 6 - Cementite particle size distribution. Symbols are the experimental results, lines represent the fitting of the experimental results using Eq. [1]. 
Table III. Cementite Particle Size, Volume Fractions of Cementite Particles, and Aspect Ratio

\begin{tabular}{|c|c|c|c|c|c|c|c|c|}
\hline Steel & $d_{L}, \mu \mathrm{m}$ & $\sigma_{L}, \mu \mathrm{m}$ & $f_{L}$ & $d_{S}, \mu \mathrm{m}$ & $\sigma_{S}, \mu \mathrm{m}$ & $f_{S}$ & Total Cementite Fraction & $\begin{array}{c}\text { Aspect } \\
\text { Ratio }\end{array}$ \\
\hline $0.5 \mathrm{Cr}^{*}$ & 0.42 & 0.17 & 0.74 & 0.13 & 0.02 & 0.26 & 0.13 & 1.4 \\
\hline $1.5 \mathrm{Cr}$ & 0.41 & 0.17 & 0.70 & 0.13 & 0.02 & 0.30 & 0.13 & 1.5 \\
\hline $2.5 \mathrm{Cr}$ & 0.44 & 0.18 & 0.70 & 0.13 & 0.02 & 0.30 & 0.13 & 1.4 \\
\hline $3.5 \mathrm{Cr}$ & 0.47 & 0.20 & 0.70 & 0.14 & 0.02 & 0.30 & 0.14 & 1.4 \\
\hline
\end{tabular}

* Data after improved spheroidization heat treatment.

spheroidization, expressed as the average aspect ratio, shows that the cementite in all steels is sufficiently spheroidized. The spheroidization of high-carbon steels with different $\mathrm{Cr}$ contents results in a bimodal distribution of cementite particles, where almost $30 \mathrm{vol}$ pct of the particles have a mean size of $0.13 \mu \mathrm{m}$ and the rest have a mean size of 0.41 to $0.47 \mu \mathrm{m}$. It should be noted that the bimodal distribution arises from the particles formed at the austenite grain boundary and the particles formed within austenite grains. Verhoeven ${ }^{[5]}$ made a similar observation of bimodality in the particle size distribution in hypereutectoid steels. In this research, almost the same size and size distributions of cementite particles are observed after spheroidization of steels with different $\mathrm{Cr}$ contents, and the hardness for all steels is approaching the optimal value for good machinability. This illustrates that by proper control of the heat treatment parameters, similar microstructures can be obtained independent of the $\mathrm{Cr}$ content (with an exception for the $0.5 \mathrm{Cr}$ steel, where the boundary cementite is spheroidized but not completely eliminated).

\section{DISCUSSION}

In hypereutectoid steels, the decomposition of austenite containing cementite particles can occur either by the pearlitic reaction or by the DET reaction, depending on the austenitization process and cooling rates. Although the existence of the DET reaction has been known for years, only a limited number of studies of the mechanism and especially of the effect of alloying elements on the DET reaction are available. The work has mainly been performed on SAE 52100 bearing steel, ${ }^{[3-12]}$ for which the achievement of a well-spheroidized structure is necessary before the subsequent machining and further bainitic or martensitic heat treatment. ${ }^{[15,16]}$

This work has shown that a change in $\mathrm{Cr}$ content in hypereutectoid steels has a significant influence on the cementite spheroidization process. The austenitization of high-Cr steels can be performed at higher temperatures without the promotion of the pearlitic reaction, which is opposite to the effect of Mn experimentally found by Verhoeven ${ }^{[5]}$ and Beswick. ${ }^{[12]}$ It is possibly not only due to an increase of the $A^{\prime}{ }_{1}$ temperature with $\mathrm{Cr}$ content, but also because $\mathrm{Cr}$ is a very strong carbide former leading to a sufficient amount of cementite even at austenitization temperatures as high as $A^{\prime}{ }_{1}+75 \mathrm{~K}$, and coarsening/dissolution of cementite is slower due to $\mathrm{Cr}$ additions. The advantage of using such high austenitization temperatures is the increased possibility to dissolve the grain-boundary cementite network present in the initial pearlitic microstructure. In low-Cr steel it is necessary to decrease the austenitization temperature to $A^{\prime}{ }_{1}+40 \mathrm{~K}$ in order to promote the DET reaction, i.e., to reduce the particle spacing after the austenitization treatment.

A kinetic model for the DET reaction has recently been proposed by Verhoeven. ${ }^{[17]}$ This model assumes that during austenite to ferrite transformation carbon diffuses away from the moving interface, both into austenite and ferrite toward the pre-existing cementite particles. The carbon diffusion fluxes make the cementite particles grow without nucleation of new cementite particles. Verhoeven ${ }^{[17]}$ has analyzed the carbon flux balance at the austenite-ferrite interface located between two cementite particles and has shown that the rate of the DET reaction can be expressed as a function of the cementite particle spacing at the austenitization temperature and the degree of undercooling at which the ferrite formation starts. It is clear that large undercoolings lead to high interface velocities and large particle spacings necessitate considerable carbon diffusion for the DET reaction, so that both (large undercoolings and large particle spacings) favor the pearlitic reaction. Verhoeven ${ }^{[17]}$ has also compared the DET growth velocities for an $\mathrm{Fe}-\mathrm{C}$ alloy with that of pearlite growth, and found a transition line for undercoolings and particle spacings below which the DET reaction is completed before pearlite has had time to nucleate.

In this research, the undercoolings are found from the dilatometry experiments as $\Delta T=A_{1}-T_{\text {start }}$, where $T_{\text {start }}$ is the austenite-ferrite transformation starting temperature. The particle spacings at the austenitization temperatures are calculated with DICTRA software, assuming that the initial particle size is about $0.4 \mu \mathrm{m}$. The fact that the intercritical spheroidization process was studied allows us to assume that pearlite lamellae have already been broken during heating and the dissolution of cementite particles occurs during the isothermal holding at austenitization temperatures. This assumption is supported by metallurgical observations on the samples quenched immediately after reaching the austenization temperature. For the well-spheroidized microstructures, the particle spacing at austenitization temperatures can also be estimated using results of the optical microscopy. The number of particles per unit area is the same at room and austenitization temperatures, since there is no 
nucleation of new particles during the DET reaction. The distances between particles at austenitization temperature are found to be close to that calculated with DICTRA, which shows that the assumption for the initial particle size is reasonably accurate.

Since the addition of alloying elements changes the phase diagram, the carbon concentrations at the interface, the rate of particle dissolution at austenitization treatment, etc., the transition line can be significantly different for different alloys. The transition line in the graph of cementite particle spacing vs undercooling is calculated using Verhoeven's approach ${ }^{[17]}$ considering the influence of $\mathrm{Cr}$ on the phase diagram (Figure 7(a)). Note that each line represents the transition between the pearlitic and the DET reaction for a particular alloy. The predicted transition line shifts upward with increasing $\mathrm{Cr}$ content (Figure 7(a)). It is shown that the austenitization temperature/time region leading to particle spacings for which the DET reaction will occur upon cooling becomes larger with an increasing amount of $\mathrm{Cr}$ (Figure 7(a)). Thus the difficulties in spheroidization of the low-Cr steels can now be explained. For a successful spheroidization of low-Cr steel, the austenitization time and temperature must be chosen such that the particle spacing before the cooling process is not more than 0.8 to $0.9 \mu \mathrm{m}$ (Figure 7(a)). If particle

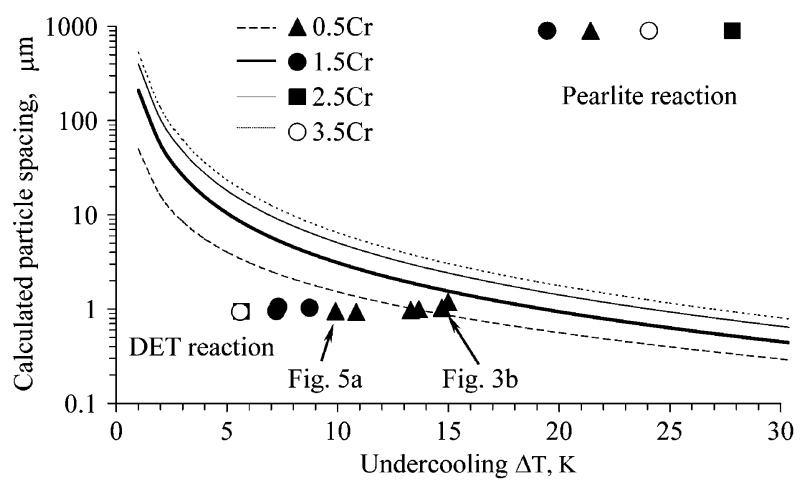

(a)

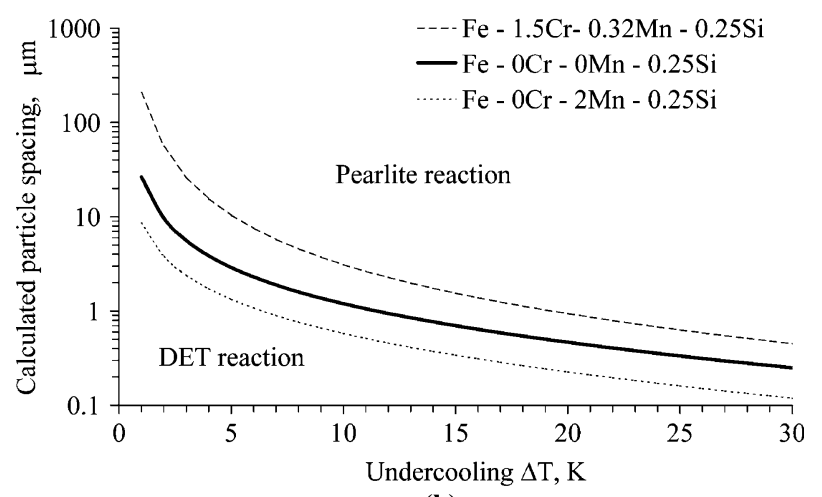

(b)

Fig. 7-(a) Transition lines for cementite particle spacing vs undercooling for steels with different $\mathrm{Cr}$ contents. Symbols show experimentally determined undercoolings, whereas particle spacing for each case was calculated with DICTRA software. Arrows show which particle spacings/undercoolings belong to the microstructures of Figs. 3(b) and 5(a). (b) Effect of $\mathrm{Mn}$ and $\mathrm{Cr}$ on the transition line between the pearlitic and DET reaction. spacing is larger than 0.8 to $0.9 \mu \mathrm{m}$, slower cooling rates than used in the present work must be considered $(5 \mathrm{~K} / \mathrm{h})$. The transition lines are in agreement with the experimental results (Figure 7(a), symbols). The symbols below the transition line show the experimentally observed spheroidized structures, and symbols above the transition line demonstrate the fully pearlitic structures. Triangles $(0.5 \mathrm{Cr}$ steel $)$ in the vicinity of the transition line refer to microstructures that have not been completely spheroidized (Figure 3(b)) and exhibited both pearlitic and spheroidized cementite.

Using this approach, the design of the spheroidization process becomes significantly easier. By analyzing the transition lines for the different alloys, the right cementite particle spacing (the combination of the austenitization temperature and time) and the cooling rate can be chosen without performing a range of long experiments in order to successfully obtain spheroidized structures. For instance, the pearlite-promoting effect of Mn experimentally observed in the literature ${ }^{\{5,12]}$ can now also be predicted using the described approach (Figure 7(b)).

\section{CONCLUSIONS}

The effect of $\mathrm{Cr}$ on the spheroidization process has been studied, and the following can be concluded.

1. Spheroidized microstructures in hypereutectoid steels with different $\mathrm{Cr}$ contents are obtained after intercritical spheroidization heat treatment, i.e., by the promotion of the DET reaction. A bimodal distribution of spheroidized cementite particles is observed.

2. The DET reaction occurs at lower undercoolings compared with the pearlitic reaction, and the promotion of the DET reaction depends strongly on the carbide particle spacing at the austenitization treatment.

3. Chromium has a significant effect on the spheroidization process. Chromium addition increases the austenitization temperature/time region for which the DET reaction will occur upon cooling. In low-Cr or Cr-free steels the promotion of the DET reaction becomes difficult. A proper control of the cementite particle spacing at the austenitization treatment and the cooling rate helps to overcome this problem and to obtain sufficiently spheroidized structure in low-Cr steels as well.

\section{ACKNOWLEDGMENTS}

The authors gratefully acknowledge the industrial partners SKF and Corus Group, particularly Drs. J. Slycke, R.H. Vegter, R. Mostert, and Mr. P. Neuman for their continuous interest in this research.

\section{OPEN ACCESS}

This article is distributed under the terms of the Creative Commons Attribution Noncommercial License which permits any noncommercial use, distribution, 
and reproduction in any medium, provided the original author(s) and source are credited.

\section{REFERENCES}

1. K.E. Thelning: Steel and Its Heat Treatment, Butterworth and Co., London, 1984, pp. 207-12.

2. W. Knorr and H. Vöge: in Steel. A Handbook for Materials Research and Engineering, vol. 1, Verein Deutscher Eisenhüttenleute, ed., Düsseldorf, 1992, pp. 589-603.

3. S. Chattopadhyay and C.M. Sellars: Metallography, 1977, vol. 10, pp. 89-105.

4. D. Hernandez-Silva, R.D. Morales, and J.G. Cabanas-Moreno: ISIJ Int., 1992, vol. 32, pp. 1297-305.

5. J.D. Verhoeven: Metall. Mater. Trans. A, 2000, vol. 31A, pp. 2431-38.

6. E.L. Brown and G. Krauss: Metall. Trans. A, 1986, vol. 17A, pp. $31-36$.

7. F.J. Vermolen, E. Javierre, C. Vuik, L. Zhao, and S. van der Zwaag: Comput. Mater. Sci., 2007, vol. 39, pp. 767-74.
8. E.B. Damm and M.J. Merwin: in Austenite Formation and Decomposition, G.M. Michal and M.D. Novak, eds., TMS, Warrendale, PA, 2003, pp. 397-413.

9. W. Hewitt: Heat Treat. Met., 1982, vol. 3, pp. 56-62.

10. R.F. Mehl and W.C. Hagel: Prog. Met. Phys., 1956, vol. 6, pp. 74 134.

11. T. Oyama, O.D. Sherby, J. Wadsworth, and B. Walser: Scripta Metall., 1984, vol. 18, pp. 799-804.

12. J.M. Beswick: Metall. Trans. A, 1987, vol. 18A, pp. 1897-1906.

13. A. Borgenstam, A. Engström, L. Höglund, and J. Agren: J. Phase Equilibria, 2000, vol. 21, pp. 269-80.

14. A.M. Cree, F.G. Foulkner, and A.T. Lyne: Mater. Sci. Technol., 1995, vol. 11, pp. 566-71.

15. L. Zhao, F.J. Vermolen, A. Wauthier, and J. Sietsma: Metall. Mater. Trans. A, 2006, vol. 37A, pp. 1841-50.

16. N. Luzginova, L. Zhao, and J. Sietsma: Mater. Sci. Eng. A, 2007, vol. 448, pp. 104-10.

17. J.D. Verhoeven and E.D. Gibson: Metall. Mater. Trans. A, 1998, vol. 29A, pp. 1181-89. 